\title{
Standards for the predictive accuracy of short term body height and lower leg length measurements on half annual growth rates
}

\author{
M HERMANUSSEN AND J BURMEISTER* \\ Department of Paediatrics, Children's Hospital and *Institute for Information Science and Practical \\ Mathematics, University of Kiel, Federal Republic of Germany
}

SUMmARY Determinations of body height and calculations of growth velocity are still the major parameters for the assessment of normal and aberrant growth. The present study was performed to investigate the minimum time interval between consecutive measurements that is necessary for a statement on significant length increment both of total body height and lower leg length. We present standards for the predictive accuracy of short term measurements for the prediction of the conventional half annual growth rate. We also provide centiles of the predictive error that occurs when the difference between two consecutive measurements is used to determine a half annual growth rate.

Accurate determination of body height and calculation of growth velocity $(\mathrm{cm} /$ year) are the major parameters for the assessment of normal and aberrant growth. Standards of growth velocity exist for annual growth rates, and it has become general practice also to use half annual growth rates for the estimation of a child's growth. Yet, as early as 1971, Marshall published his findings on growth rate in 260 children over periods of less than one year, and he concluded that a child's growth rate over the three months of fastest growth is most frequently two to three times his slowest growth rate- that is, that a satisfactory assessment of a child's growth cannot be made over periods of less than one year. ${ }^{1}$ Nevertheless, the discussions on minimum time intervals necessary for the estimation of a valid growth rate are still continuing.

Recent findings on lower leg growth strongly suggest that growth rate is not constant. ${ }^{23}$ This may also be true for growth in height, but this has never been shown in a similarly convincing way. Under these circumstances, however, it becomes obvious that short sections of a primarily non-linear growth curve may never be used for the prediction of a mean linear increment of a longer section of the same growth curve.

The present study was performed to provide standards and centiles of the error that occurs when differences of consecutive short term measurements of height are used to calculate long term (half annual) growth rates.

\section{Patients and methods}

A total of 119 children of both sexes, aged between 4.5 and 14.9 years, were studied. The children comprised those who were normal and those with various untreated growth disorders such as Turner's syndrome, partial growth hormone deficiency, Russell-Silver syndrome, Marfan's syndrome, and unclassified syndromes associated with short or tall stature. They were measured once or twice weekly by Harpenden stadiometer and knemometry ${ }^{4-6}$ over periods between 161 and 202 (mean 186) days for 11 to 50 times. All measurements were done by the same trained observer. All children were measured at exactly the same time of the day (plus or minus 30 minutes) between noon and 4.00 pm under standardised circumstances as described earlier. ${ }^{4}$ The technical error of the measurement of body height was $\mathrm{SD}=1.5 \mathrm{~mm}$, the technical error of the lower leg length measurement (knemometry) was $0.16 \mathrm{~mm}$ and, thus, a little higher than reported previously. ${ }^{5}$ The limit of discrimination of the lower leg length measuring device was $0.1 \mathrm{~mm}$, thus providing integer values of lower leg length at a scale of $0 \cdot 1$ $\mathrm{mm}$. At each visit three measurements of body height and four measurements of lower leg length 
were taken. The present analysis was based on the medians of the height measurements and the medians of three (four minus the first) lower leg length measurements. Growth rates were calculated in the conventional way: that is, by dividing the length difference of consecutive measurements by the time interval.

The predictive accuracy of short term measurements was investigated in the following way: for each child, the 'conventional' half annual growth rates (both of body height and lower leg length) were calculated in order to determine the basis for the following calculation. These growth rates consisted of the length differences between the first and the last measurements of each individual growth curve divided by the respective time intervals (161 to 202 days). Each individual growth rate was defined as $100 \%$ of the 'conventional' individual half annual growth yielding a relative and strictly individual frame for growth determinations in each child. Thereafter, each growth curve was cut into as many short intervals as possible yielding up to 1225 intervals per growth curve ranging from a few days to close to six months. Again, growth rates were calculated using the length differences between the first and the last measurements of each interval, divided by the time between the respective measurements. These short term growth rates were compared with their respective individual growth frames, that is, with the respective individual 'conventional' half annual growth rates and expressed as percentage of these rates.

By these means, we gained 119 individual 'con- ventional' half annual growth rates that could be compared with a total of 37093 short term growth rates. This procedure was performed for growth both of body height and lower leg length. For comparison, we were interested in producing a simulation of a growth curve with a defined linear trend (straight linear increment) and a defined variance. ${ }^{7}$ In analogy to real knemometric growth curves we anticipated a mean half annual increment of $1 \mathrm{~cm}$ per 186 days and a technical error of 0.16 $\mathrm{mm}$. As lower leg lengths are given at discrete intervals of $0.1 \mathrm{~mm}$, we constructed a sample of fixed integer values $(n=186)$ in the following way:

(1) We randomly computed 186 integer values within a range of -5 to +5 . For this purpose we used a binomial distribution characterised by $\mathrm{n}=10, \mathrm{p}=\frac{1}{2}$. This produced a variance of $\mathrm{np}(1-\mathrm{p})=10 \frac{1}{2} \cdot \frac{1}{2}=2 \cdot 5$, yielding a standard deviation of $\sqrt{2 \cdot 5}=1 \cdot 6$, which is in good approximation of the observed technical error of $0.16 \mathrm{~mm}(1.6$ times the discrete interval of $0 \cdot 1 \mathrm{~mm}$ ).

(2) We transformed these data linearly resulting in a linear trend $(y(x)=a x+b)$ with $a=\frac{100}{186}$.

Because knemometric growth data must be interpreted as integer values, we preferred to simulate a binomial distribution instead of a Gaussian distribution. $^{8}$

\section{Results}

All children were growing during the observation period. Half annual height increments ranged be-

Table 1 Mean (SD) short term length increments associated with individual 'conventional' half yearly growth rates $(100 \%)$

\begin{tabular}{|c|c|c|c|}
\hline $\begin{array}{l}\text { Interval between } \\
\text { consecutive measurements } \\
\text { (days) }\end{array}$ & $\begin{array}{l}\text { No of } \\
\text { intervals }\end{array}$ & $\begin{array}{l}\text { Percentage body } \\
\text { height increments } \\
\text { Mean }(S D)\end{array}$ & $\begin{array}{l}\text { Percentage lower } \\
\text { leg length increments } \\
\text { Mean }(S D)\end{array}$ \\
\hline 7 & 1748 & $98(453)$ & $108(181)$ \\
\hline 14 to 20 & 2680 & $95(225)$ & $101(100)$ \\
\hline 21 to 27 & 2423 & $100(158)$ & $100(77)$ \\
\hline 28 to 34 & 2338 & $101(124)$ & $99(62)$ \\
\hline 42 to 50 & 3300 & $103(84)$ & $100(47)$ \\
\hline 51 to 60 & 2462 & $104(72)$ & $101(39)$ \\
\hline 61 to 70 & 3012 & $102(60)$ & $102(37)$ \\
\hline 71 to 80 & 2082 & $103(54)$ & $101(32)$ \\
\hline 81 to 90 & 1928 & $103(45)$ & $100(28)$ \\
\hline 91 to 100 & 2281 & $103(43)$ & $100(26)$ \\
\hline 101 to 110 & 1556 & $103(38)$ & $99(22)$ \\
\hline 111 to 120 & 1678 & $103(37)$ & $100(20)$ \\
\hline 131 to 140 & 1219 & $102(31)$ & $100(15)$ \\
\hline 141 to 150 & 827 & $102(28)$ & $100(13)$ \\
\hline 151 to 160 & 699 & $101(25)$ & 99 (12) \\
\hline 161 to 170 & 633 & 99 (22) & $99(10)$ \\
\hline $171+$ & 382 & $99(16)$ & $99(8)$ \\
\hline
\end{tabular}


tween $1 \cdot 1$ and $5.5 \mathrm{~cm} / \mathrm{six}$ months, half annual lower leg length increments ranged between 0.3 and 2.0 $\mathrm{cm} / \mathrm{six}$ months. Table 1 summarises means and standard deviations (SD) of short term body height increments and lower leg length increments at selected intervals compared with their respective individual 'conventional' half annual growth rates (expressed as percent of these rates). It is evident that mean short term growth rates stay very close to the $100 \%$ line. Yet, it takes 35 days until the SD of short term height measurements approaches the $100 \%$ limit, and more than 71 days until $95.5 \%$ of short term height measurements provide an estimate of the 'conventional' half annual growth rate within a range of plus-minus $100 \%$ (SD drops below $50 \%$ ).

Fig 1 describes graphically how the SD of body height and lower leg growth prediction declines with time at a double logarithmic scale. Figs 2 and 3 provide analogous information to table 1 summarising the accuracy of growth prediction in terms of centiles. Knemometry provides better estimations of half annual growth, but it takes still more than 35 days until the SD of the predictive error falls below $50 \%$.

For comparison we have provided table 2 . It shows the simulation of a lower leg growth curve with a constant growth rate of $1.0 \mathrm{~cm} / \mathrm{six}$ months (100 times the discrete interval of $0.1 \mathrm{~mm}$ ) and a technical error of $0.16 \mathrm{~mm}$. The table is given in analogy to the previous table and offers an additional comparison between the simulated variance (second column, squared values) and the experimentally found variance of lower leg growth prediction (last column, table 1 , values in parenthesis, squared) for each interval between consecutive measurements. The comparison is done by dividing the simulated variance by the experimental variance and the result given as a percentage. It is

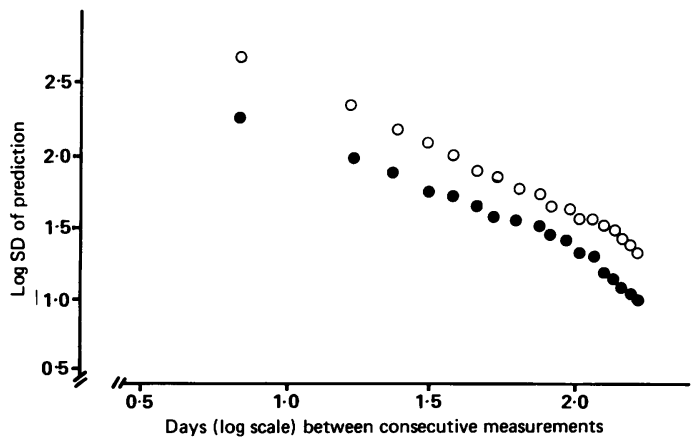

Fig 1 SD of growth prediction of body height (open circles) and lower leg length $(X)$. The data are derived from table 1.

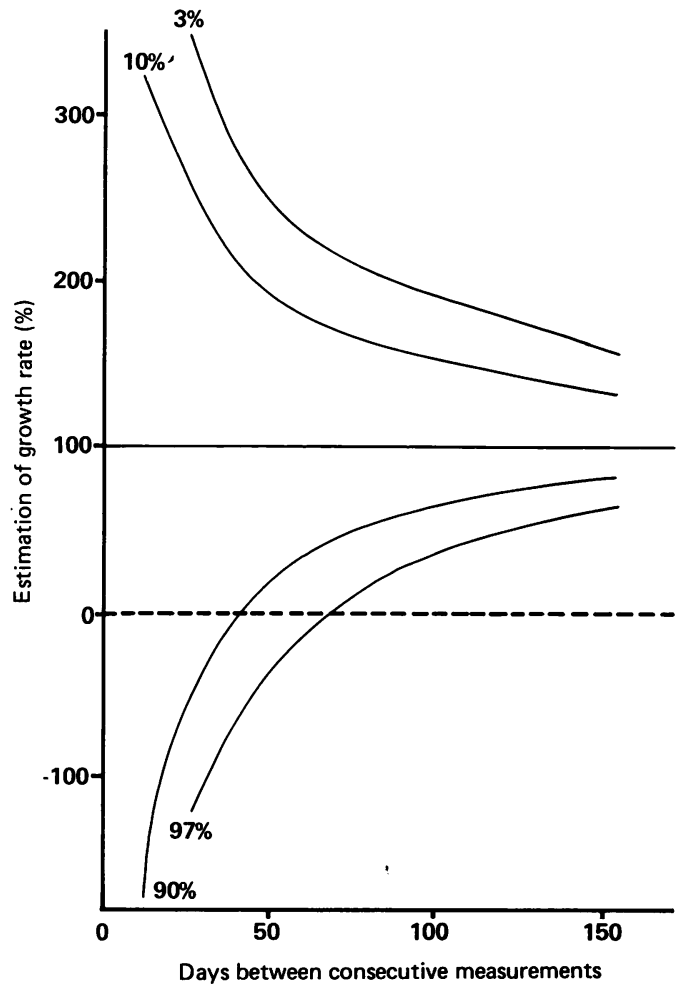

Fig 2 Centiles of the predictive error of growth prediction (estimate of the half yearly linear increment) of height from short term differences. The linear half yearly increment ('conventional' half yearly growth rate) is indicated by the $100 \%$ line. The curved lines indicate the centiles of the probability within which the error of the estimate may be found. The magnitude of the error is expressed as a percentage of the linear half yearly increment.

obvious that the technical error (simulated variance) mainly accounts for the variance of those predictions that are derived from measurements at close intervals, whereas this error is unimportant for predictions from measurements taken at longer intervals.

In addition, we were interested in children with comparably low and comparably high half annual growth rates. We selected 18 children by random with lower leg growth rates between 0.30 and 1.73 $\mathrm{cm} / \mathrm{six}$ months. We then investigated a 'standard deviation score', that is, we recalculated each short term relative growth rate of these individuals and expressed it in terms of SD of the respective short term interval (table 1). For example, a 35 days' growth rate of $160 \%$ of the 'conventional' half annual lower leg growth rate is an over estimation of $60 \%$. At day 35 the SD of the predictive error is 


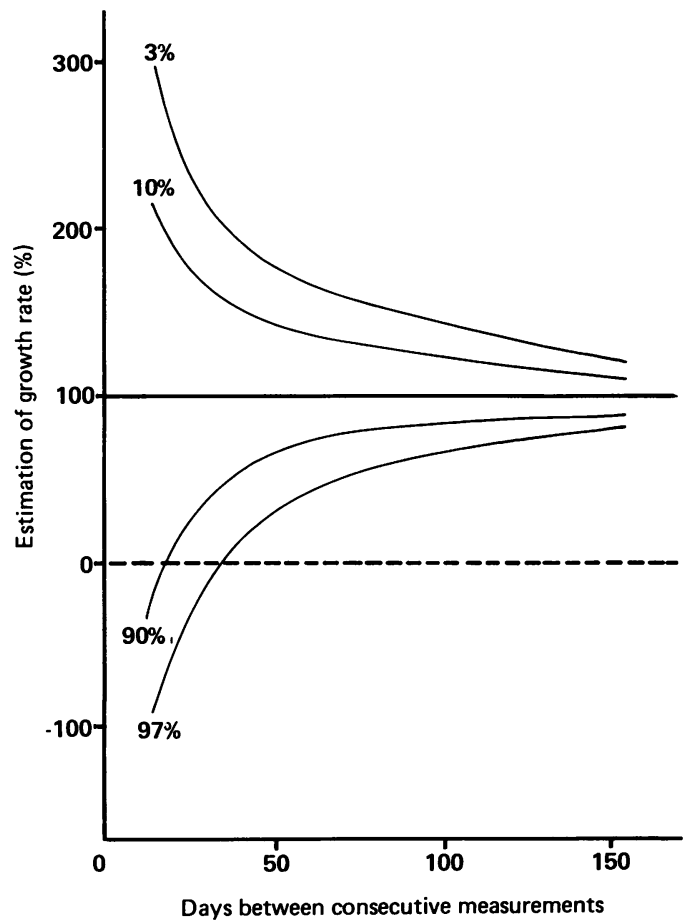

Fig 3 Centiles of the predictive error of the estimation of the half yearly linear increment in lower leg length.

$54 \%$ (table 1). Thus an over estimation of $60 \%$ is equivalent to 1.12 times the SD of the time interval of 35 days, and thus equals an 'SD score' of $+1 \cdot 12$. For each individual, we calculated an individual mean absolute 'SD score' according to:

$$
\frac{1}{n} \sum_{i=1}^{n} \frac{\left|\mathbf{x}_{i}^{(\mathbf{k})}-\overline{\mathbf{x}}^{(\mathbf{k})}\right|}{\sigma^{(\mathbf{k})}}
$$

with $\mathbf{n}=$ number of short term growth rates; $\sigma=$ standard deviation of the respective (k) short term interval; and $\mathrm{k}=$ respective short term interval (table 1). We then plotted a $\chi^{2}$ table (table 3$) .{ }^{7}$ The children were divided according to the following parameters: (a) half annual growth rate above or below $1 \mathrm{~cm} / \mathrm{six}$ months; (b) mean absolute 'SD score' above or below 1 .

This table is significant with $\chi^{2}=9.16$ at $p<0.01$. Children with high growth rates tend to show lower 'SD scores' than those with low growth rates. Thus short term growth estimations in terms of percentage of 'conventional' half annual growth rates are generally better in children with high growth rates.
Table 2 Standard deviation of selected short increments of a simulated growth curve with a linear trend of 100 $(1.0 \mathrm{~cm} / \mathrm{six}$ months) and a variation of $S D=1.6(0.16 \mathrm{~mm})$, and a ratio of simulated variance:experimental variance

\begin{tabular}{lll}
\hline $\begin{array}{l}\text { Interval between } \\
\text { consecutive } \\
\begin{array}{l}\text { measurements } \\
\text { (days) }\end{array}\end{array}$ & $\begin{array}{l}\text { Standard deviation } \\
\text { of simulated } \\
\text { length increments }\end{array}$ & $\begin{array}{l}\text { Percentage } \\
\text { ratio of } \\
\text { simulated: } \\
\text { experimental } \\
\text { variance }\end{array}$ \\
\hline 3 & 282 & $30 \cdot 3$ \\
7 & 59 & $10 \cdot 6$ \\
14 to 20 & 26 & $6 \cdot 6$ \\
21 to 27 & 18 & $5 \cdot 4$ \\
28 to 34 & 14 & $4 \cdot 8$ \\
35 to 41 & 11 & $4 \cdot 2$ \\
71 to 80 & 5 & $2 \cdot 9$ \\
101 to 110 & 4 & $3 \cdot 2$ \\
121 to 130 & 3 & $4 \cdot 4$ \\
151 to 160 & 3 & $4 \cdot 4$ \\
\hline
\end{tabular}

Table $3 \chi^{2}$ table of 18 randomly chosen children distributed according to half annual growth rate and mean absolute standard deviation score

\begin{tabular}{lll}
\hline & $\begin{array}{l}\text { Fast growing } \\
\text { (half yearly } \\
\text { growth rate } \\
>1 \mathrm{~cm} / \text { six } \\
\text { months) }\end{array}$ & $\begin{array}{l}\text { Slow growing } \\
\text { (half yearly } \\
\text { growth rate } \\
<1 \mathrm{~cm} / \text { six } \\
\text { months) }\end{array}$ \\
\hline $\begin{array}{l}\text { Mean absolute } \\
\text { standard deviation } \\
\text { score }>1\end{array}$ & 0 & 7 \\
$\begin{array}{l}\text { Mean absolute } \\
\text { standard deviation } \\
\text { score <1 }\end{array}$ & 8 & 3 \\
\hline
\end{tabular}

$\chi^{2}=9 \cdot 16$ at $\mathrm{p}<0.01$.

\section{Discussion}

In 1971 Marshall concluded that a satisfactory assessment of a child's growth cannot be made over periods of less than one year. ${ }^{1}$ This conclusion was derived from series of monthly measurements using length differences between single measurements rather than sophisticated mathematical procedures as this was done later by Wit $e$ al in order to prove that lower leg length increments were not constant. ${ }^{3}$ Thus the question has not been answered properly whether the observed variation of the measured height increments may be entirely attributed to variation of growth rate rather than to the variation due to the error of the measurement itself.

Due to the fact that the measurement of body height is less accurate than the measurement of the lower leg length ${ }^{5}$ the above question has only been solved for the latter. Lower leg growth rate is not 
constant. ${ }^{4910}$ This is partially caused by an appreciable day to day variation of the measured lower leg length that exceeds the error of measurement significantly, ${ }^{49}$ and by periodical changes of growth velocity at intervals between 30 and 55 days. ${ }^{11}$ Particularly the day to day variation of the measured lower leg length with a range of more than $\pm 1 \mathrm{~mm}^{4}$ prohibits the derivation of a 'growth rate' from single differences of lower leg length measurements if obtained at close intervals. Yet, this has largely been disregarded in recent clinical studies where three week and four week 'growth rates' had been obtained to provide information on short term growth. ${ }^{12} 13$

The present study quantifies (in terms of centiles) the relative error that is inherent in the prediction of 'conventional' long term growth rates from single determinations of length at intervals less than six months apart. As shown above, there are at least three different sources that contribute to the error of prediction: (a) the technical error of the measurement; (b) the day to day variation of the lower leg length; and (c) the periodicity of lower leg length increments. We have provided evidence that the technical error mainly accounts for the variance of predictions derived from measurements which are very close together, whereas this error is almost unimportant for differences between consecutive measurements at longer intervals. As it is difficult to distinguish mathematically between the day to day variation of the measured lower leg length and the periodicity of growth, we have not quantified these sources separately.

It may be argued that the assumption of a constant error (which would be appropriate if most of the error is instrumental) would make it more appropriate to present the SDs in absolute rather than percentage terms as there is no particular reason to assume that a high growth rate would give more variable results (in absolute terms) than a low one. We were interested in a more general description in the first place, however, including both fast and slow growing children. Therefore, we deliberately decided to use a relative rather than an absolute parameter for the description of the predictive error. We answered this particular question in a second step, and in fact, table 3 shows that children with high growth rates are systematically less variable in percentage terms. Thus in the case of a relative (centile based) estimation of the error of growth prediction, there is a fourth source that contributes significantly to the inaccuracy of growth prediction: that is, the absolute growth velocity of the child.
The centiles of the predictive error of body height measurements are very similar to those of the lower leg length measurements. Thus similar conclusions may be drawn regarding the validity of growth rate determinations from differences of single height measurements. If information on the process of growth is required within intervals of less than three months, measurements of body height are inadequate. This information may only be provided by knemometry, though not by rare single measurements, but by series of lower leg length determinations which have to be analysed either using polynomials $^{3}$ or techniques similar to the moving average as proposed earlier. ${ }^{210} 11$

\section{References}

${ }^{1}$ Marshall WA. Evaluation of growth rates in height over periods of less than one year. Arch Dis Child 1971;46:414-20.

2 Hermanussen M, Sippell WG. Changes of short term growth velocity (mini-growth-spurts) in 36 healthy children, measured twice weekly by knemometry. Ann Hum Biol 1985;1 (suppl): 79 .

${ }^{3}$ Wit JM, van Kalsbek EJ, van Wijk-Hoek J, Lepping GJ. Assessment of the usefulness of weekly knemometric measurements in growth studies. Pediatr Res 1986;20:1196.

${ }^{4}$ Hermanussen M, Geiger-Benoit K, Burmeister J, Sippell WG. Knemometry in childhood: accuracy and standardization of a new technique of lower leg length measurement. Ann Hum Biol 1988;15:1-16.

5 Valk IM, Langhout Chabloz AME, Smals AGH, Kloppenborg PWC, Cassorla F, Schutte EAST. Accurate measurement of the lower leg length and the ulnar length and its application in short term growth measurement. Growth 1983;47:53-66.

6 Wales JKH, Milner RDG. Knemometry in assessment of linear growth. Arch Dis Child 1987;62:166-71.

7 Kreyszig E. Statistische Methoden und ihre Anwendung. Göttingen: Vandenhoek and Ruprecht, 1982.

${ }^{8}$ Bratley P, Fox BL, Schrage LE. A guide to simulation. New York: Springer, 1983.

9 Hermanussen M, Sippell WG, Valk IM. Knemometric monitoring of early effects of human growth hormone on leg length in children with growth hormone deficiency. Lancet 1985;i: 1069-71.

10 Hermanussen M, Geiger-Benoit K, Burmeister J, Sippell WG. Can the knemometer shorten the time for growth rate assessment? Acta Paediatr Scand 1987;337(suppl):30-6.

11 Hermanussen M, Geiger-Benoit K, Burmeister J, Sippell WG. Periodical changes of short term growth velocity (mini-growthspurts) in human growth. Ann Hum Biol 1988;15:103-9.

12 Gelato MC, Ross JL, Malozowski S, et al. Effects of pulsatile administration of growth hormone (GH)-releasing hormone on short term linear growth in children with GH deficiency. J Clin Endocrinol Metab 1985;61:444-50.

13 Ross JL, Long LM, Skerda M, Cassorla FG, Loriaux, Cutler GB. Growth response relationship between growth hormone dose and short term growth in patients with Turner's syndrome. J Clin Endocrinol Metab 1986;63:1028-30.

Correspondence to Dr M Hermanussen, Universitätskinderklinik, Schwanenweg 20, 2300 Kiel, Federal Republic of Germany.

Accepted 19 July 1988 